\title{
Crescimento e respostas fisiológicas do meloeiro inoculado com fungos micorrízicos arbusculares sob estresse salino
}

\section{Growth and physiological responses of melon plants inoculated with mycorrhizal fungi under salt stress}

\author{
Wilber da Silveira Lúcio ${ }^{1}$; Claudivan Feitosa de Lacerda ${ }^{2 *}$; \\ Paulo Furtado Mendes Filho²; Fernando Felipe Ferreyra Hernandez ${ }^{2}$; \\ Antonia Leila Rocha Neves ${ }^{3}$; Enéas Gomes-Filho ${ }^{2}$
}

\begin{abstract}
Resumo
Nas regiões áridas e semiáridas é comum a acumulação de sais no solo em quantidades prejudiciais ao crescimento e rendimento das plantas. Neste contexto, os fungos micorrízicos arbusculares (FMA) vem sendo estudados nos últimos anos, havendo resultados que indicam que as associações micorrízicas com as plantas minimizam alguns efeitos do estresse salino. O objetivo foi avaliar os efeitos da inoculação dos fungos micorrízicos arbusculares na cultura do meloeiro sob estresse salino. $\mathrm{O}$ delineamento experimental utilizado foi o inteiramente casualizado, em arranjo fatorial $2 \times 4$, correspondendo a 2 tratamentos micorrízicos (plantas inoculadas e não inoculadas) e 4 níveis de salinidade (CEa): 0,5, 1,5, 3,0 e 4,5 dS m ${ }^{-1}$, com 4 repetições. Foram avaliadas a colonização micorrízica, o crescimento, as trocas gasosas foliares e os teores e conteúdos de $\mathrm{N}, \mathrm{P}, \mathrm{K}^{+}, \mathrm{Na}^{+}$e $\mathrm{Cl}^{-}$nas plantas. A associação com FMA proporcionou um incremento na produção matéria seca da parte aérea e na área foliar; porém, este efeito benéfico decresceu com o aumento da salinidade. Os FMA também influenciaram de forma positiva a condutância estomática, taxa de transpiração e fotossintética. Os resultados mostraram um pico de colonização na $\mathrm{CEa}$ de $1,36 \mathrm{dS} \mathrm{m}^{-1}$ com tendência de redução a partir deste nível de salinidade. Verificou-se ainda que a associação simbiótica entre FMA e meloeiro proporcionou aumento nos totais extraídos de $\mathrm{N}, \mathrm{P}$ e $\mathrm{K}^{+}$, principalmente nos níveis baixos e médios de salinidade, e redução na absorção dos íons potencialmente tóxicos $\left(\mathrm{Na}^{+} \mathrm{e} \mathrm{Cl}^{-}\right)$a partir da salinidade da água de irrigação de $3,0 \mathrm{dS} \mathrm{m}^{-1}$.

Palavras-chave: Cucumis melo L., salinidade, micorriza, fotossíntese, nutrição mineral
\end{abstract}

\begin{abstract}
The accumulation of salts in the soil is a common problem of arid and semi-arid regions, that cause reduction in plant growth and yield. In this context, the arbuscular mycorrhizal fungi (AMF) have been studied in recent years, with results indicating that their associations with the plant roots minimize some effects of salt stress. The objective of this work was to evaluate the influence of increasing levels of salinity of the irrigation water in the melon plants mycorrhized with AMF. The experiment design was completely randomized in factorial $2 \times 4$ corresponding to two mycorrhiza treatments (inoculated and not inoculated plants) $\mathrm{x} 4$ levels of salinity $\left(\mathrm{ECw}=0.5,1.5,3.0\right.$ and $\left.4.5 \mathrm{dS} \mathrm{m}^{-1}\right)$, with 4 replicates. The mycorhizal colonization, plant growth, leaf gas exchange and the concentrations and contents of ions $\left(\mathrm{N}, \mathrm{P}, \mathrm{K}^{+}, \mathrm{Na}^{+}\right.$e $\left.\mathrm{Cl}^{-}\right)$were measured. The mycorrhized plants showed higher production of shoot dry
\end{abstract}

\footnotetext{
${ }^{1}$ Ms em Solos e Nutrição de Plantas, Universidade Federal do Ceará, UFC, Fortaleza, CE. E-mail: wilberlucio@yahoo.com.br

${ }^{2}$ Profs. do Centro de Ciências Agrárias, CCA, UFC, Fortaleza, CE. E-mail: cfeitosa@ufc.br; mendes@ufc.br; ferrey@ufc.br; egomesf@ufc.br

${ }^{3}$ Doutoranda em Engenharia Agrícola, CCA, UFC, Fortaleza, CE. E-mail: leilaneves7@hotmail.com

* Autor para correspondência
} 
matter and leaf area, in relation to non-inoculated plants, mainly in the $0.5 \mathrm{dS} \mathrm{m}^{-1}$ treatment. However, this beneficial effect decreased with salinity levels increasing. Stomatal conductance, transpiration rate and photosynthetic rate were positively influenced by AMF, the values being higher in mycorrhized plants. The results showed a peak of colonization in treatment with EC of $1.36 \mathrm{dS} \mathrm{m}^{-1}$ with a tendency to decrease in higher salt concentrations. The symbiotic association between AMF and melon roots increased the contents of $\mathrm{N}, \mathrm{P}$ and $\mathrm{K}$, at low and medium salinity, and reduced the absorption of potentially toxic ions $(\mathrm{Na}, \mathrm{Cl})$ from the salinity caused by irrigation water with $3.0 \mathrm{dS} \mathrm{m}^{-1}$.

Key words: Cucumis melo L, salinity, mycorrhiza, photosynthesis, mineral nutrition

\section{Introdução}

O melão (Cucumis melo L.) é originário de regiões tropicais e, dessa forma, condições de clima quente e umidade relativa baixa favorecem o melhor desenvolvimento das plantas, além de propiciar alta produtividade e frutos de excelentes qualidades (GRANGEIRO et al., 2002). Devido a essas características, inúmeras variedades de melão são cultivadas em regiões semiáridas em todo o mundo. Entretanto, nessas regiões, a salinização do solo se constitui um sério problema que vem limitando a produção agrícola e reduzindo a produtividade das culturas.

Além das técnicas convencionais de manejo do sistema solo-água-planta, um aspecto que vem sendo recentemente estudado para manter os rendimentos das culturas em áreas afetadas pela salinidade é o emprego de plantas colonizadas com fungos micorrízicos arbusculares (FMA). De acordo com vários autores, a maior absorção de nutrientes, propiciada pela colonização das raízes por FMA, melhora o estado nutricional das plantas e favorece seu crescimento quando cultivadas em ambiente salino, em comparação com as plantas não colonizadas (GIRI; KAPOOR; MUKERJI, 2003; DODD; PÉREZ-ALFOCEA, 2012). Al-Karaki (2000), em estudo com o tomateiro submetido a níveis crescentes de salinidade, afirmam que as plantas inoculadas com FMA apresentam maiores teores de $\mathrm{P}, \mathrm{Fe}, \mathrm{Cu}$ e $\mathrm{Zn}$ que as plantas não inoculadas, sendo que esse resultado está relacionado à maior absorção e/ou translocação desses nutrientes pelas hifas do fungo. Outros estudos também constataram a maior absorção de nutrientes pelas plantas associadas ao FMA quando cultivadas sob estresse salino (AL-KARAKI; HAMMAD; RUSAN, 2001; SHARIFI; GHORBANLI; EBRAHIMZADEH, 2007).

As alterações das variáveis microbiológicas (respirometria, colonização, carbono da biomassa microbiano, quociente metabólico, dentre outras) no ambiente radicular das plantas colonizadas com FMA submetidas a estresse salino são pouco relatadas na literatura e apresentam resultados muito variados. Essas variações de resultados podem estar associadas tanto às características intrínsecas do fungo quanto a sua capacidade de germinação ou de infectar a planta sob condições salinas ou às características fisiológicas ou fenológicas do hospedeiro. Em bananeiras inoculadas com diferentes espécies de FMA cultivadas sob diferentes níveis de salinidade, verificou-se um comportamento diferenciado da colonização das raízes em relação às espécies fúngicas associadas às plantas (YANO-MELO; SAGGIN; MAIA, 2003). Saint-Etienne et al. (2006), em estudo com Pterocarpus officinalis (Jacq.) nas estações chuvosa e seca, verificaram que a percentagem de colonização de FMA diminuiu linearmente com o aumento da salinidade do solo. Asghari et al. (2005), em estudo com Atriplex nummularia, também verificaram diminuição na colonização de raízes por FMA com o aumento da salinidade e que essa colonização foi maior em plantas no seu ambiente natural $(30 \%)$ do que cultivadas em casa de vegetação $(1 \%$ a $2 \%$ ). Conforme os mesmos autores, essa diferença na percentagem de colonização foi atribuída a fatores e interações entre os FMA e o hospedeiro, característicos das condições de campo.

De acordo com Al-Karaki (2000), os benefícios 
propiciados pelos FMA, como aumento no crescimento e na aquisição dos nutrientes pelas plantas, demonstram o potencial da colonização do FMA para a proteção do cultivo de plantas sob estresse salino em regiões áridas e semiáridas. Nesse sentido, o objetivo deste trabalho foi avaliar a colonização micorrízica, o crescimento, as trocas gasosas foliares e a absorção de íons em plantas de melão irrigadas com água com níveis crescentes de sais e inoculadas ou não com FMA.

\section{Material e Métodos}

O experimento foi conduzido em casa de vegetação localizada no Campus do Pici da Universidade Federal do Ceará, em Fortaleza/ CE (34' S, 38 33' $\mathrm{W}, 20 \mathrm{~m})$, utilizando argissolo vermelho amarelo retirado da camada arável $(0-20$ $\mathrm{cm})$ de uma área também localizada no Campus do Pici, o qual apresentava as seguintes características: textura arenosa, densidade do solo $-1,5 \mathrm{~kg} \mathrm{dm}^{-3}$, $\mathrm{pH}-5,6, \mathrm{CE}_{1: 1}-0,13 \mathrm{dS} \mathrm{m}{ }^{-1}, \mathrm{PST}-3,4 \%, \mathrm{P}-9,8$

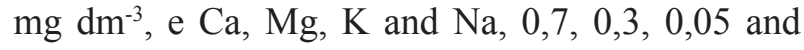
$0,06 \mathrm{cmol} \mathrm{dm}^{-3}$, respectivamente. A temperatura média no interior da casa-de-vegetação no decorrer do experimento foi de $30,6^{\circ} \mathrm{C} \pm 4,5^{\circ} \mathrm{C}$. Segundo a classificação de Köeppen, a região apresenta um clima do tipo Aw'.

Utilizou-se no experimento sementes comerciais do melão (Cucumis melo L. variedade Inodorus). As sementes foram superficialmente esterilizadas com uma solução de hipoclorito de sódio a 5\% (v/v), seguida por lavagens com água destilada para retirada do excesso da substância esterilizante. Foram utilizados vasos perfurados com 4,0 kg de solo seco ao ar, destorroado, peneirado em tamis de 2,0 mm e esterilizado por autoclavagem durante $2 \mathrm{~h}$ a $127{ }^{\circ} \mathrm{C}$ e $1 \mathrm{~atm}$ de pressão. As sementes de melão foram semeadas em setembro e, após sete dias, foi realizado o desbaste, deixando-se uma planta por vaso, efetuando-se a primeira aplicação de solução nutritiva.
$\mathrm{O}$ delineamento experimental utilizado foi $\mathrm{o}$ inteiramente casualizado, em arranjo fatorial $2 \mathrm{x}$ 4, correspondendo a 2 tratamentos micorrízicos (plantas inoculadas e não inoculadas) e 4 níveis de salinidade da água de irrigação (CEa): 0,$5 ; 1,5$; 3,0 e $4,5 \mathrm{dS} \mathrm{m}^{-1}$, com 4 repetições, totalizando 32 unidades experimentais.

A inoculação com FMA foi realizada antes da semeadura, sendo o inóculo constituído de 20 g de solo contendo fragmentos de raízes colonizadas e propágulos das espécies Glomus clarum e Glomus intraradices, com cerca de 30 esporos $\mathrm{g}^{-1}$ de solo, oriundos do Banco de Inóculo do Setor de Microbiologia do Solo do Departamento de Ciências do Solo da UFC. O inoculo foi posicionado a cerca de $3 \mathrm{~cm}$ abaixo das sementes.

A aplicação de água salina teve início seis dias após o desbaste e foi realizada sempre que necessária, a cada dois ou três dias variando de acordo com o desenvolvimento das plantas, mantendo-se a cada aplicação uma fração de lixiviação de $20 \%$. Os níveis de salinidade da água de irrigação foram obtidos a partir de água destilada com adição de $\mathrm{NaCl}$ obedecendo a relação entre CEa e concentração $\left(\right.$ mmol $_{c} \mathrm{~L}^{-1}=\mathrm{CE}$ x 10$)$.

A solução nutritiva utilizada no experimento foi a de Hoagland e Arnon (EPSTEIN, 1975), entretanto a sua composição foi modificada, com a omissão do fósforo, considerando a importância da colonização micorrízica na aquisição desse nutriente. No decorrer do experimento em todos os tratamentos foram realizadas seis aplicações de 200 $\mathrm{mL}$ dessa solução nutritiva.

Aos 25, 29 e 37 dias após o plantio (DAP) foram realizadas medições de trocas gasoas (taxa fotossintética líquida, da taxa de transpiração e condutância estomática) em folhas completamente expandidas, utilizando-se um analisador de gás no infravermelho (IRGA, mod. LCi, ADC System ), em sistema aberto, com fluxo de ar de $300 \mathrm{~mL} \mathrm{~min}^{-}$ ${ }^{1}$. As medições ocorreram sempre entre 8:00 e 12:00 $\mathrm{h}$, utilizando-se uma fonte de radiação artificial (cerca de $1200 \mu \mathrm{mol} \mathrm{m}^{-2} \mathrm{~s}^{-1}$ ). 
Aos 37 DAP, as plantas foram colhidas e separadas em folhas e hastes (caules + pecíolos), sendo determinada a área foliar com o medidor LI3100 (Área Meter, Li-Cor, Inc. Lincoln, NE, USA). As folhas (limbos foliares) coletadas da metade inferior (mais velhas) e superior (mais novas) das plantas foram congeladas em nitrogênio líquido e liofilizadas, enquanto as demais partes da planta foram colocadas para secagem em estufa a $60{ }^{\circ} \mathrm{C}$ durante $72 \mathrm{~h}$. A produção de matéria seca das plantas foi obtida somando-se os materiais liofilizados com os materiais secos em estufa.

A dependência micorrízica (DM) foi estimada, de acordo com metodologia descrita por Plenchette, Fortin e Furlan (1983), utilizando-se a seguinte fórmula:

$$
D M=\frac{M S \text { planta colonizada }-M S \text { planta não colonizada }}{M S \text { planta colonizada }} \times 100
$$

As raízes de cada planta foram coletadas e colocadas em álcool a 70\% para avaliação posterior da colonização micorrízica segundo a metodologia de coloração descrita por Phillips e Hayman (1970).

O material foliar, liofilizado e macerado, e os caules + pecíolos, secos em estufa a $60^{\circ} \mathrm{C}$ e moídos, foram utilizados para determinação dos teores de N, $\mathrm{P}, \mathrm{K}$ e Na, de acordo com Malavolta, Vitti e Oliveira (1997). Os teores de $\mathrm{Cl}^{-}$foram determinados de acordo com Gaines, Parker e Cascho (1984). Com os dados de teores e de produção de matéria seca das plantas, calcularam-se os totais extraídos dos respectivos elementos.
Os dados foram submetidos às análises de variância (teste F) e de regressão. A escolha dos modelos de regressões baseou-se na significância dos coeficientes de determinação aos níveis de $1 \%$ e $5 \%$ de probabilidade, utilizando-se o programa estatístico SAEG/UFV (RIBEIRO JÚNIOR, 2001).

\section{Resultados e Discussão}

Crescimento, depêndencia e colonização micorrízica

As plantas inoculadas com os FMA apresentaram um decréscimo linear na produção de matéria seca das folhas, caules + pecíolos e da parte aérea total com o aumento dos níveis de salinidade (Figuras 1a, b e c). Nas plantas não inoculadas a produção de matéria seca ajustou-se a uma tendência quadrática, sendo observada maior produção de matéria seca da parte aérea na $\mathrm{CEa}$ de $1,45 \mathrm{dS} \mathrm{m}^{-1}$ com posterior diminuição a partir deste valor. As plantas inoculadas com FMA apresentaram, em média, maior produção de matéria seca das folhas, caules + pecíolos e parte aérea total e área foliar, quando comparadas às não inoculadas, com um percentual superior de $31,34,33$ e 43\%, respectivamente (Figura 1). No entanto, as diferenças de crescimento entre as plantas inoculadas e não inoculadas decresceram nos maiores níveis de salinidade aplicados (Figura 1), indicando que nesses níveis o estresse osmótico e a toxidez iônica se tornaram mais limitantes do que a escassez de nutrientes no solo. 
Figura 1. Matéria seca das folhas (MSF) (a), dos caules + pecíolos (MSC+P) (b), e total da parte aérea (MSPA) (c) e área foliar (AF) (d) do meloeiro inoculado $(\downarrow)$ e não inoculado ( $\square$ ) com FMA submetido a níveis crescentes de salinidade. Significativo a $\mathrm{p}<0,01(* *)$ e $\mathrm{p}<0,05(*)$ pelo teste $\mathrm{F}$; NS não significativo.
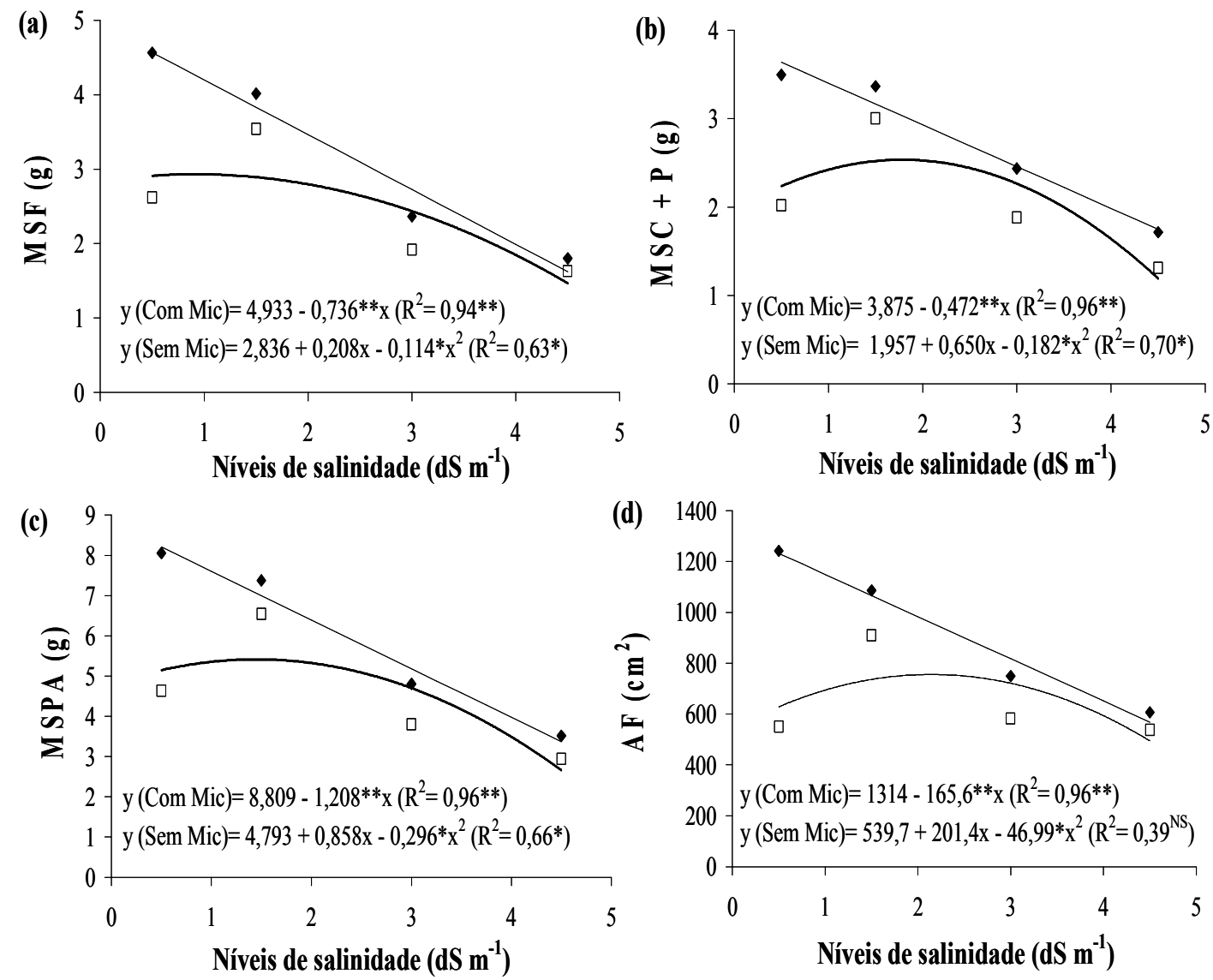

Fonte: Elaboração dos autores.

Tian et al. (2004), estudando a cultura do algodão, verificaram um aumento da matéria seca da parte aérea de até $68 \%$ nas plantas inoculadas com FMA em relação às não inoculadas, sob diferentes níveis de salinidade do solo. Yano-Melo, Saggin e Maia (2003) verificaram em bananeiras colonizadas com FMA (Glomus clarum), um aumento de 83\% da matéria seca da parte aérea em relação às não colonizadas sob diferentes níveis de salinidade. Resultados semelhantes foram encontrados por Giri, Kapoor e Mukerji (2003); Asghari et al. (2005) e Sharifi, Ghorbanli e Ebrahimzadeh (2007). Esses efeitos benéficos da inoculação com FMA têm sido atribuídos à melhoria do balanço nutricional (LAEI et al., 2011; EVELIN; GIRI; KAPOOR, 2012), à redução dos danos oxidativos causados pela salinidade (LATEF; CHAOXING, 2011), alterações no estado hormonal das plantas (DODD; PEREZALFOCEA, 2012) ou pelos efeitos indiretos sobre a comunidade microbiana do solo (ASGHARI et al., 2005).

A percentagem de dependência micorrízica (DM) (Figura 2a), levando-se em consideração todos os níveis de salinidade, foi classificada como média segundo Miranda e Miranda (2004). O maior valor de DM, cerca de $38 \%$, foi constatado nas plantas irrigadas com água de condutividade elétrica de 0,5 $\mathrm{dS} \mathrm{m}{ }^{-1}$, visto que neste tratamento foram observadas as maiores diferenças na produção de matéria seca 
entre as plantas inoculadas e não inoculadas com FMA, sendo os menores valores observadas nas sem inoculação. A partir do tratamento com CEa de $0,5 \mathrm{dS} \mathrm{m}^{-1}$, o valor da DM apresentou uma tendência de diminuição, atingindo um valor mínimo (cerca de 24\%) na CEa de 3,7 dS m ${ }^{-1}$. Em contraste, Tian et al. (2004), estudando a cultura do algodão sob níveis crescentes de salinidade, verificaram que o aumento dos níveis de $\mathrm{NaCl}$ do solo proporcionaram um aumento na DM. Tavares et al. (2012) também verificaram que a intensificação das condições de estresse salino aumentaram a dependência micorrízica das mudas de sabiá. De acordo com Daei et al. (2009), as diferentes respostas obtidas com inoculação com FMA podem estar associadas às diferentes combinações utilizadas de espécies de FMA e de plantas hospedeiras, sob condições de estresse salino.

Figura 2. Percentagem de dependência (a) e colonização (b) micorrízica em raízes de meloeiro cultivado em diferentes níveis de salinidade de água de irrigação. Significativo a $\mathrm{p}<0,01(* *)$ e $\mathrm{p}<0,05\left(^{*}\right)$ pelo teste $\mathrm{F}$.

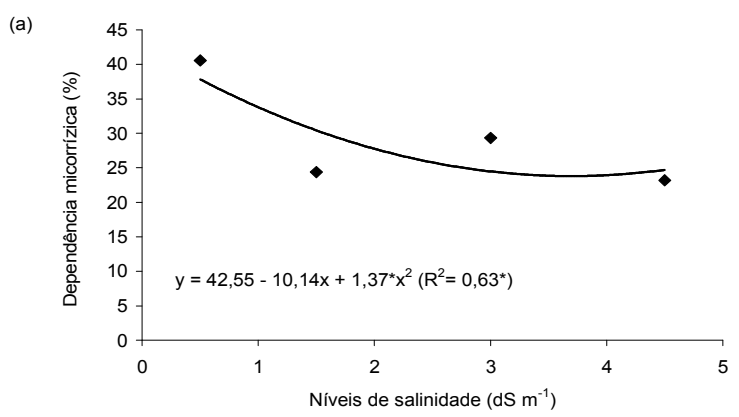

Fonte: Elaboração dos autores.

As plantas inoculadas apresentaram estruturas características de colonização micorrízica, enquanto nas plantas não inoculadas a colonização foi nula. Os resultados mostraram um pico de colonização no tratamento com CEa 1,36 dS m m $^{-1}$ com tendência de redução a partir deste valor (Figura 2b). Estudo desenvolvido com mudas de sabiá demonstrou que a colonização micorrízica com Glomus clarum, Gomus intraradices e Glomus AZ112 apresentou comportamento quadrático, alcançando o máximo em $1,71 \mathrm{dS} \mathrm{m}^{-1}$, e a partir desse ponto ocorreu decréscimo na colonozação com o aumento dos níveis de salinidade (TAVARES et al., 2012). Picos de colonização em raízes de plantas de bananeira inoculadas com Glomus clarum com posterior diminuição destes devido ao aumento dos níveis de salinidade também foram observados por Yano-Melo, Saggin e Maia (2003). Entretanto, quando estas plantas foram inoculadas à espécie

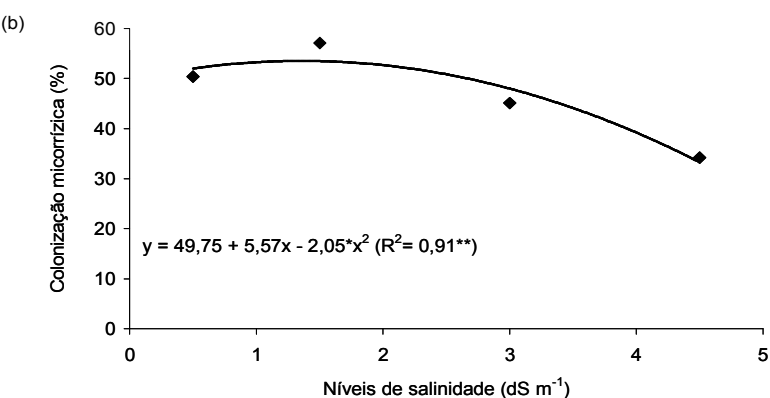

de FMA Acaulospora scrobiculata a colonização aumentou linearmente até o nível de 7,39 $\mathrm{dS} \mathrm{m}^{-1}$. Saint-Etienne et al. (2006), estudando Pterocarpus officinalis (Jacq.), e Asghari et al. (2005), estudando Atriplex nummularia, verificaram diminuição na colonização de raízes por FMA com o aumento da salinidade. Essa diminuição pode ser explicada pelo fato de que concentrações elevadas de $\mathrm{NaCl}$ no solo inibem a germinação de esporos e o comprimento de hifas/esporos de FMA (JUNIPER; ABBOTT, 2006). No entanto, a origem dos isolados de FMA (CARVALHO; CORREIA; MARTINS-LOUÇÃO, 2004), a espécie de FMA(YANO-MELO; SAGGIN; MAIA, 2003) e as condições ambientais (GARCÍA; MENDOZA, 2007; BEZERRA et al., 2010) podem resultar em diferentes respostas, tanto em termos de germinação de esporos como de colonização micorrízica. 


\section{Trocas gasosas foliares}

A condutância estomática (Figura 3a), a taxa de transpiração (Figura 3b) e de fotossíntese (Figura 3c) apresentaram tendência de diminuição em relação aos níveis de salinidade nas 3 épocas de leitura. As reduções nas trocas gasosas em função da salinidade têm sido verificadas por diversos autores, e têm sido atribuídas à causas estomáticas e não estomáticas associadas aos efeitos osmóticos e tóxicos do excesso de sais (BEZERRA et al., 2005). Aparentemente, no presente estudo, as reduções nas trocas gasosas parecem estar associadas, em grande parte, às limitações estomáticas.

As folhas das plantas inoculadas apresentaram, nas leituras feitas aos 25 DAP, menor condutância estomática(Figura 3a), transpiração(Figura3b) e taxa fotossintética líquida(Figura 3c) quando comparadas com as plantas não inoculadas. Entretanto, aos 29 e 37 DAP essa tendência mudou e as plantas inoculadas apresentaram valores significativamente maiores nas trocas gasosas foliares em todos os níveis de salinidade. Aos 29 e 37 DAP as plantas inoculadas com FMA apresentaram maior valor de $A$ quando comparadas com as não inoculadas em todos os níveis de salinidade, sendo constatado no tratamento salino a $4,5 \mathrm{dS} \mathrm{m}^{-1}$ acréscimos de $34 \%$ e 39\%, respectivamente (Figura 3c). É possível, que as maiores taxas fotossintéticas verificadas nas plantas inoculadas com FMA estejam relacionadas a uma melhor condição fisiológica proporcionada pela associação simbiótica estabelecida, visto que essas plantas apresentaram maior crescimento, demonstrando assim, a importância da associação simbiótica do meloeiro com os FMA sob condições de salinidade. Entretanto, os mecanismos pelos quais a micorrização provoca esses efeitos positivos nas trocas gasosas ainda não são conhecidos (SHENG et al., 2008).

\section{Teores de nitrogênio, fósforo e potássio}

As folhas mais novas (Figura 4a) da cultura do melão não apresentaram diferenças significativas nos teores de nitrogênio $(\mathrm{N})$ em relação aos níveis crescentes de salinidade da água de irrigação e em relação à associação simbiótica com os FMA. Por outro lado, nas folhas mais velhas das plantas inoculadas com FMA os teores de $\mathrm{N}$ ajustaram-se a uma tendência quadrática em relação aos níveis crescentes de salinidade, apresentando um aumento nos teores $\mathrm{N}$ até a salinidade $3,0 \mathrm{dS} \mathrm{m}^{-1}$ e uma posterior diminuição. Nas plantas não inoculadas os teores de $\mathrm{N}$ ajustaram-se a uma tendência linear decrescente, com redução de $1,09 \mathrm{~g} \mathrm{~kg}^{-1}$ para cada aumento unitário da salinidade da água de irrigação (Figura 4b). Nos caules + pecíolos das plantas inoculadas com FMA os teores de $\mathrm{N}$ ajustaram-se a uma tendência quadrática em relação aos níveis crescentes de salinidade, apresentando um aumento nos teores desse elemento até a salinidade de 2,33 $\mathrm{dS} \mathrm{m} \mathrm{m}^{-1}$ e uma posterior diminuição (Figura 4c). Nas plantas não inoculadas com FMA os teores de $\mathrm{N}$ também se ajustaram a uma tendência quadrática, entretanto o comportamento dos teores de $\mathrm{N}$ foi inverso ao observado nas plantas inoculadas, decrescendo até a CEa de 3,12 $\mathrm{dS} \mathrm{m}^{-1}$ e aumentando a partir deste valor de salinidade. 
Figura 3. Condutância estomática (a), taxa de transpiração (b) e taxa fotossintética (c) em folhas maduras de meloeiro inoculado (ロ) e não inoculado com FMA ( $\square)$, em função dos níveis de salinidade da água de irrigação e de leituras feitas ao longo do desenvolvimento vegetativo (25, 29 e 37 DAP). As barras representam o erro padrão.
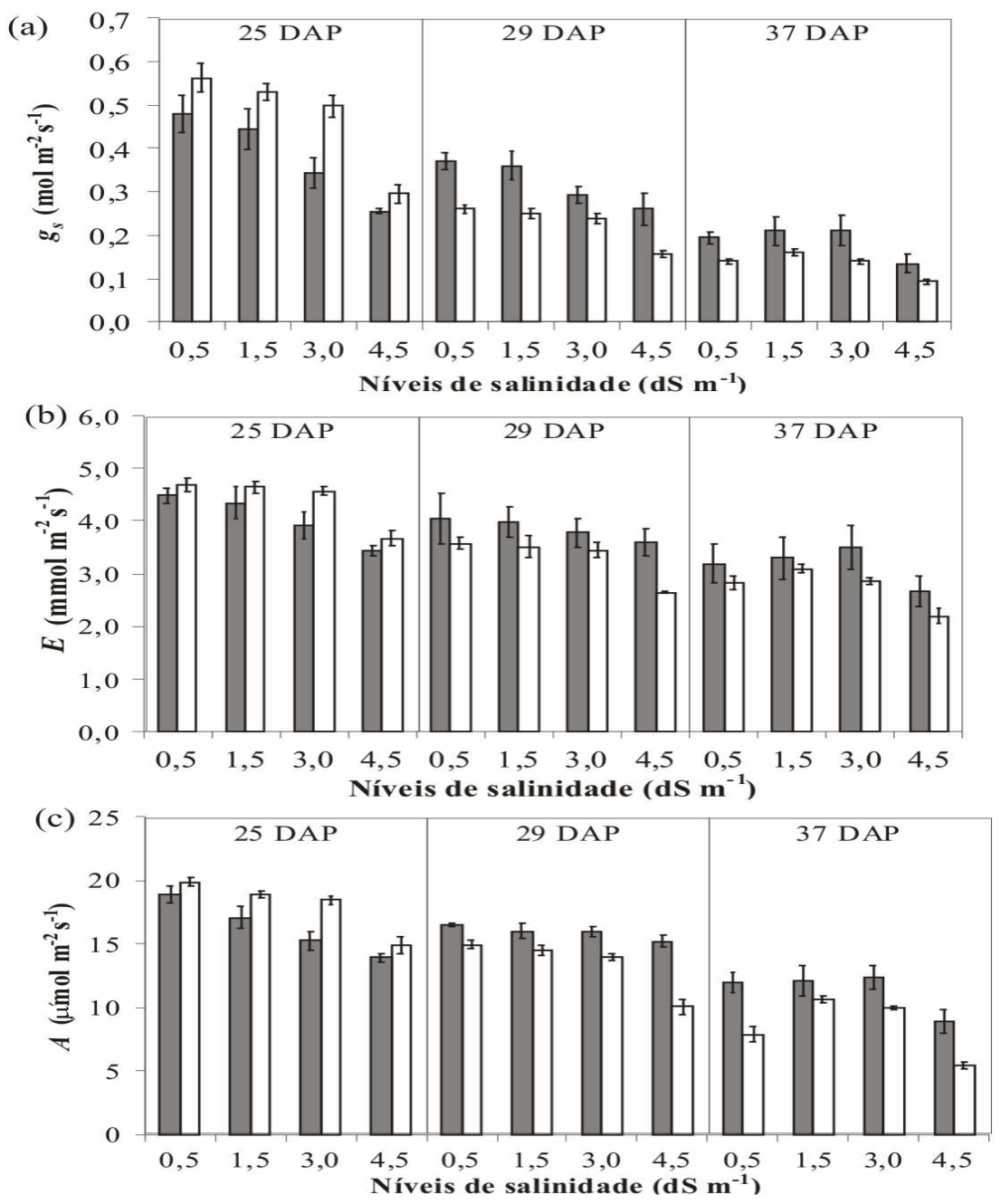

Fonte: Elaboração dos autores. 
Figura 4. Teores de nitrogênio nas folhas mais novas (a), folhas mais velhas (b) e caules + pecíolos (c), e total extraído por planta (d) em meloeiro inoculado ( ) e não inoculado ( $\square$ ) com FMA cultivado em níveis crescentes de salinidade. Significativo a $\mathrm{p}<0,01(* *)$ e $\mathrm{p}<0,05\left(^{*}\right)$ pelo teste $\mathrm{F}$.
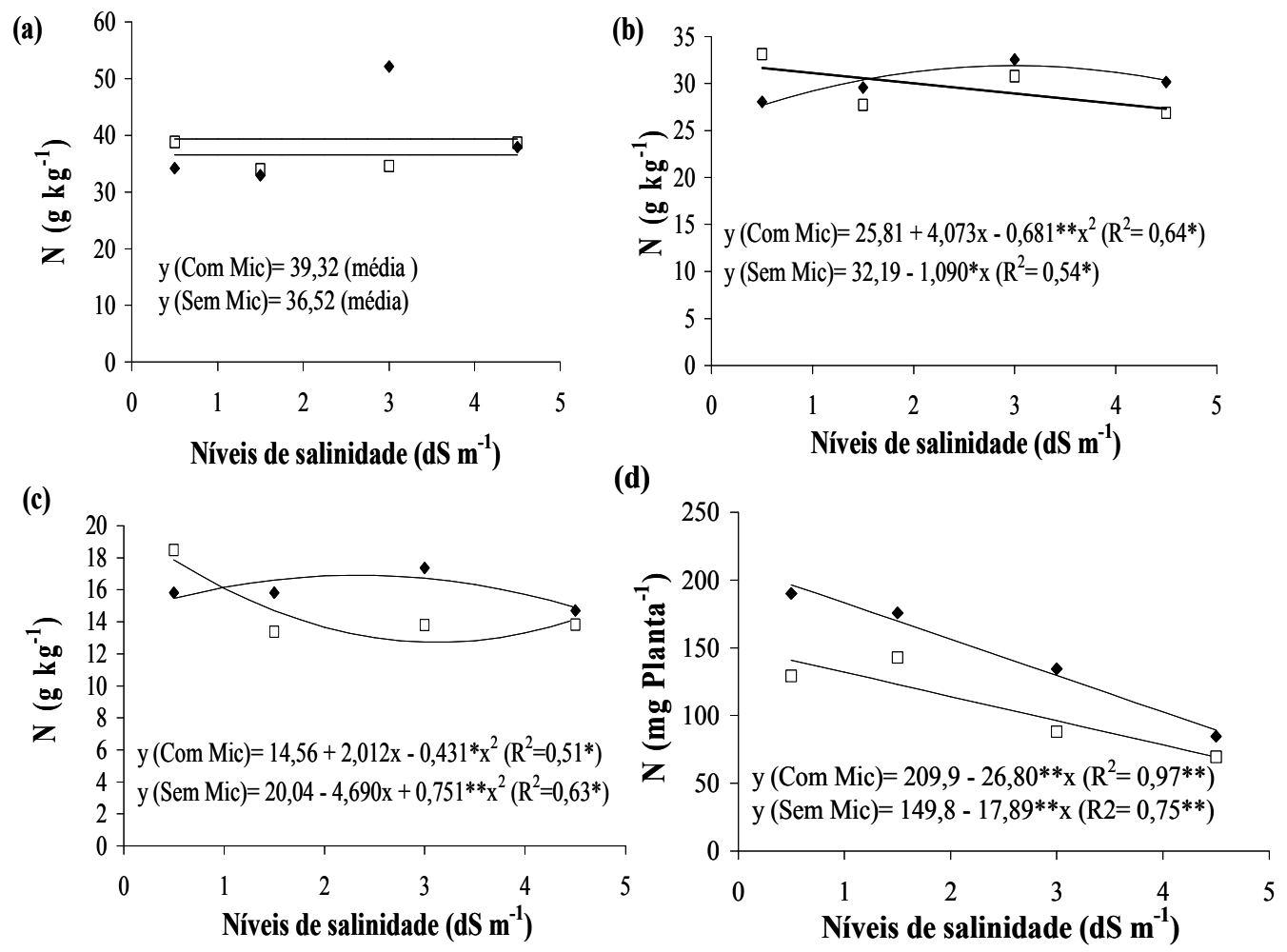

Fonte: Elaboração dos autores.

Cantrell e Linderman (2001), estudando alface e cebola não inoculadas e inoculadas com espécies de FMA isoladas de áreas salinas e não salinas, verificaram que os teores de nitrogênio da parte aérea diferiram apenas nas plantas de cebola, verificandose que as plantas não inoculadas com FMA foram as que tiveram os maiores teores de $\mathrm{N}$ em todos os níveis de salinidade $\left(2,4,8\right.$ e $\left.12 \mathrm{dS} \mathrm{m}^{-1}\right)$.

$\mathrm{O}$ conteúdo de $\mathrm{N}$ decresceu linearmente com o aumento nos níveis de salinidade (Figura 4d), com reduções de $26,8 \mathrm{mg}$ planta $^{-1}$ nas que receberam inoculação e de $17,89 \mathrm{mg} \mathrm{planta}^{-1}$ nas não inoculadas com FMA, para cada aumento unitário na salinidade da água de irrigação. Apesar do maior grau de redução do conteúdo de $\mathrm{N}$ nas plantas inoculadas com FMA, verifica-se que elas apresentaram maior conteúdo desse nutriente em todos os níveis de salinidade. Possivelmente, esse fato está relacionado à maior eficiência das plantas inoculadas com FMA na produção de matéria seca (Figura 1) e também aos maiores teores de $\mathrm{N}$ nas folhas mais velhas (Figura $4 b$ ) e nos caules + pecíolos (Figura 4c) destas plantas. Ruiz-Lozano e Azcón (2000), estudando o cultivo de alface associado aos fungos micorrízicos arbusculares em condições de estresse salino, também observaram que as plantas inoculadas com FMA apresentaram um aumento no conteúdo de $\mathrm{N}$ em relação às não inoculadas sob condições crescentes de salinidade.

Quando se analisa o teor de P verifica-se que apenas nos caules + pecíolos é que ocorreram diferenças significativas entre os tratamentos 
micorrízicos (Figuras 5a, b e c). Nas plantas inoculadas com FMA os teores de P apresentaram uma tendência linear crescente com o aumento dos níveis de salinidade, enquanto que nas plantas não inoculadas a tendência foi quadrática, com uma diminuição dos teores de $\mathrm{P}$ até o nível de salinidade de $2,76 \mathrm{dS} \mathrm{m}^{-1}$ e um posterior aumento (Figura $5 \mathrm{c}$ ).
$\mathrm{O}$ aumento nos teores de $\mathrm{P}$ nos caules + pecíolos, sob condições de salinidade, está relacionado à maior eficiência de absorção de $\mathrm{P}$ proporcionada pela associação com os FMA, visto que as plantas inoculadas com FMA apresentaram também maior crescimento (Figura 1) e maiores teores de $\mathrm{P}$ que as plantas não inoculadas.

Figura 5. Teores de fósforo nas folhas mais novas (a), folhas mais velhas (b) e caules + pecíolos (c), e total extraído por planta (d) em meloeiro inoculado ( $\downarrow)$ e não inoculado ( $\square$ ) com FMA cultivado em níveis crescentes de salinidade. Significativo a $\mathrm{p}<0,01(* *)$ e $\mathrm{p}<0,05\left(^{*}\right)$ pelo teste $\mathrm{F}$.
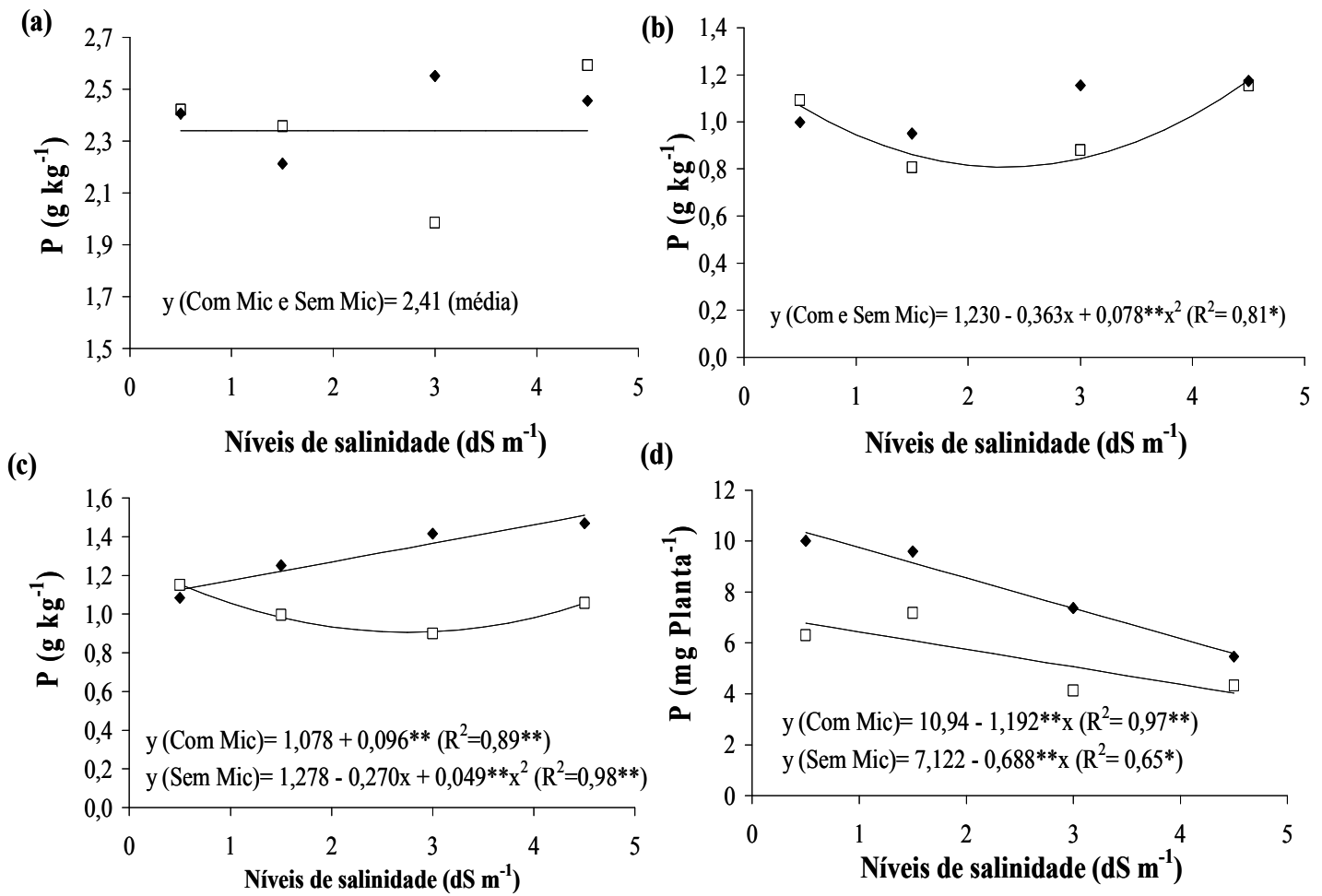

(d)

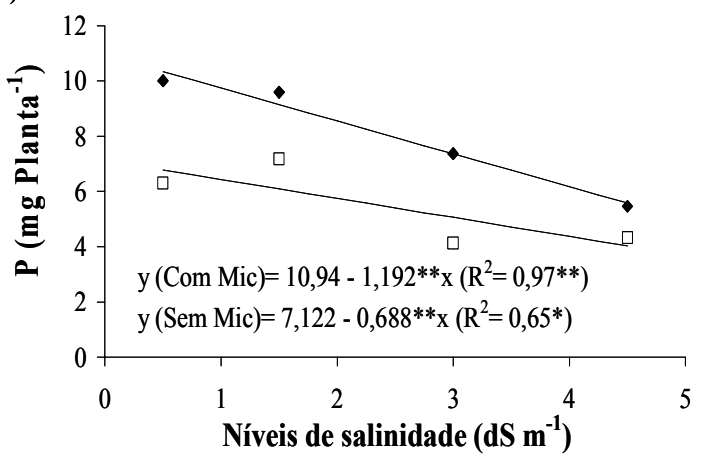

Fonte: Elaboração dos autores.

Al-Karaki (2000), verificou que o cultivo de tomate em níveis crescentes de salinidade da água de irrigação proporcionou a diminuição dos teores de $\mathrm{P}$ da parte aérea tanto nas plantas inoculadas como nas não inoculadas com FMA, tendo as primeiras apresentado maiores teores desse nutriente. Sharifi, Ghorbanli e Ebrahimzadeh (2007), estudando a cultura do sorgo, também verificaram que os teores de $\mathrm{P}$ da parte aérea das plantas inoculadas e das não inoculadas com FMA decresceram com níveis crescentes de $\mathrm{NaCl}$ e que as plantas colonizadas pelo fungo apresentaram um maior teor de $\mathrm{P}$ que as não colonizadas em praticamente todos os níveis, com exceção das que receberam $200 \mathrm{mM}$ de $\mathrm{NaCl}$, nas quais os teores de $\mathrm{P}$ foram estatisticamente iguais para as duas condições de inoculação.

$\mathrm{O}$ conteúdo de $\mathrm{P}$ decresceu linearmente com o aumento da salinidade, tanto nas plantas inoculadas quanto nas não inoculadas com FMA (Figura 5d). No entanto, analisando-se essas linhas de tendência nota-se que a associação com os FMA proporcionou 
maior absorção de $\mathrm{P}$ em relação às plantas não inoculadas. Esses resultados, possivelmente, estão relacionados à maior eficiência das plantas na produção de MS e na absorção de $\mathrm{P}$ quando associadas aos fungos micorrízicos arbusculares. Al-karaki, Hammad e Rusan (2001) também encontraram reduções no conteúdo de $\mathrm{P}$ com o aumento da salinidade tanto nas plantas inoculadas quanto nas não inoculadas com FMA.

A salinidade afetou os teores de $\mathrm{K}$ nas plantas, porém essa resposta dependeu da parte da planta analisada e dos tratamentos com FMA (Figura 6). Nas folhas mais novas os efeitos da salinidade foram significativos apenas nas plantas não inoculadas (Figura 6a), enquanto que nas folhas mais velhas o grau de redução foi maior nas plantas inoculadas (Figura 6b). Nos caules + pecíolos ocorreram reduções lineares nas plantas inoculadas e não inoculadas, mas a taxa de decréscimo foi maior nas que não receberam inoculação com FMA(Figura 6c). Sharifi, Ghorbanli e Ebrahimzadeh (2007) também encontraram diminuições nos teores de potássio na parte aérea de plantas de soja submetidas a estresse salino. Os mesmos autores também verificaram que as plantas inoculadas com FMA quando comparadas com as não inoculadas apresentaram maior teor de $\mathrm{K}$, na maioria dos tratamentos com $\mathrm{NaCl}$, com exceção dos tratamentos de maior concentração desse sal (150 e $200 \mathrm{mM})$, nos quais os teores de $\mathrm{K}$ foram estatisticamente iguais. A redução na absorção de $\mathrm{K}$ possivelmente está associada ao processo competitivo com o $\mathrm{Na}$ que se encontra em excesso na solução do solo sob salinidade (MARSCHNER, 1995; MAATHUIS; AMTAMANN, 1999).

Figura 6. Teores de potássio nas folhas mais novas (a), folhas mais velhas (b) e caules + pecíolos (c), e total extraído por planta (d) em meloeiro inoculado ( $\downarrow$ ) e não inoculado ( $\square$ ) com FMA cultivado em níveis crescentes de salinidade. Significativo a $\mathrm{p}<0,01(* *)$ e $\mathrm{p}<0,05(*)$ pelo teste $\mathrm{F}$; ${ }^{\text {NS }}$ não significativo.

(a)
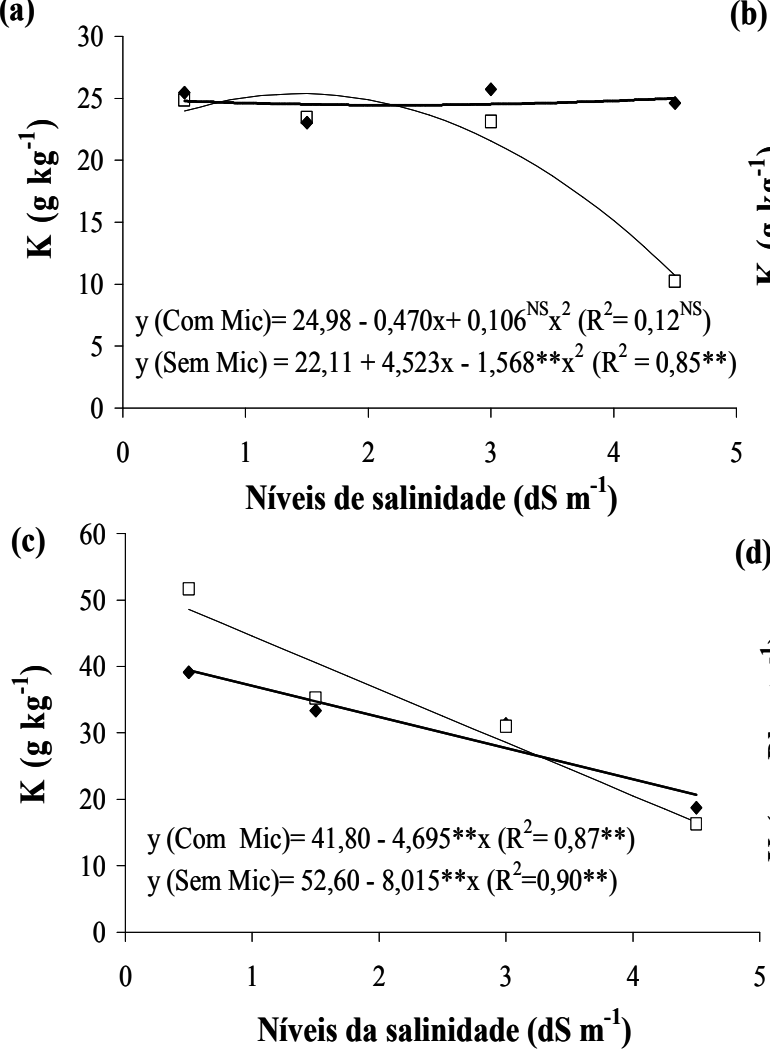

(b)

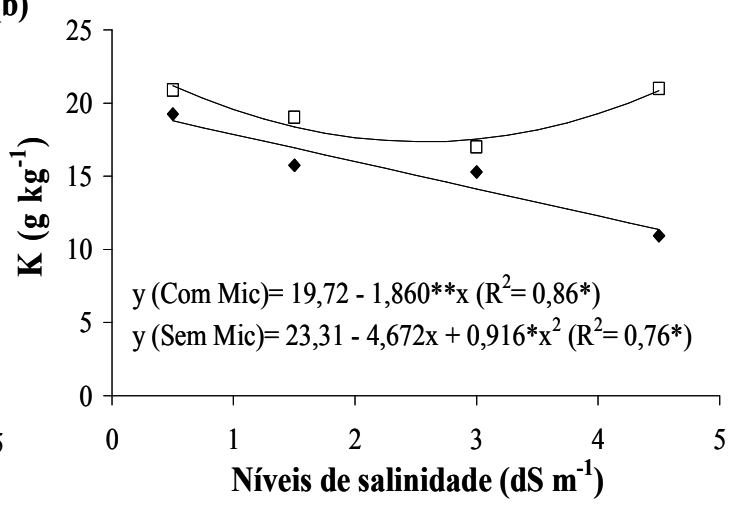

Fonte: Elaboração dos autores.

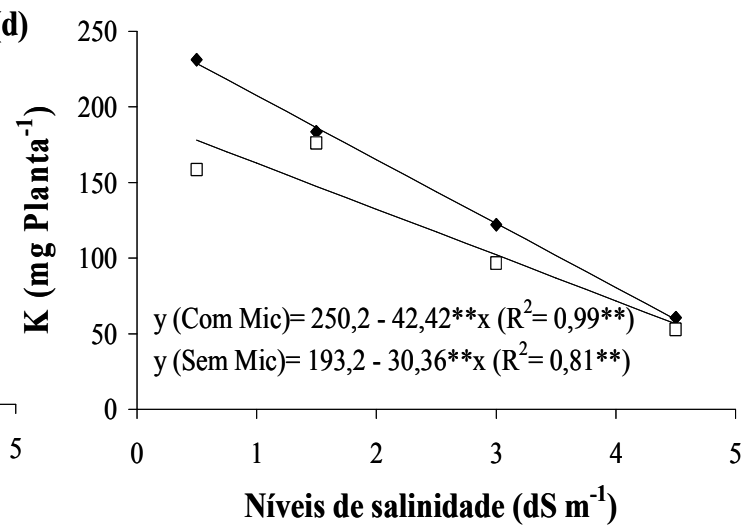


Tanto as plantas inoculadas quanto as não inoculadas com FMA apresentaram tendência linear de diminuição do conteúdo de $\mathrm{K}$ em relação aos níveis crescentes de salinidade (Figura 6d). As plantas inoculadas com FMA apresentaram maior conteúdo de $\mathrm{K}$ quando comparadas com as não inoculadas, entretanto as diferenças entre essas plantas decresceram nos maiores níveis de salinidade. Al-karaki, Hammad e Rusan (2001) verificaram maiores conteúdos de $\mathrm{K}$ em plantas de tomate inoculadas com FMA quando estas foram submetidas a baixa $\left(1,4 \mathrm{dS} \mathrm{m}^{-1}\right)$ e média $\left(4,9 \mathrm{dS} \mathrm{m}^{-1}\right)$ salinidade da água de irrigação, entretanto em alta salinidade $\left(7,1 \mathrm{dS} \mathrm{m}^{-1}\right)$ o conteúdo de $\mathrm{K}$ das plantas inoculadas com FMA foi estatisticamente igual ao das plantas não inoculadas.

Em geral, têm sido observados aumentos nas concentrações e nos totais extraídos de N, P e K em plantas inoculadas com FMA sob condições de salinidade, tanto em condições controladas como no campo (LAEI et al., 2011; LATEF; CHAOXING, 2011; MARDUKHI et al., 2011). Esses resultados estão de acordo com a maioria dos autores que destaca que a principal contribuição do FMA está relacionada com a aquisição de nutrientes, estando as plantas ou não sob condições de estresse. Os resultados obtidos no presente estudo estão parcialmente de acordo com os mencionados acima, principalmente quando se comparam os totais extraídos pelas plantas.

\section{Sódio e cloreto}

Os resultados de $\mathrm{Na}$ (Figura 7a, b e c) e Cl (Figuras $8 \mathrm{a}, \mathrm{b}$ e c) apresentaram aumentos quadráticos em função dos níveis de salinidade, sendo os maiores teores encontrados nos caules + pecíolos e menores nas folhas mais novas, evidenciando, de certa forma o mecanismo de retenção desses íons, que limita o seu acúmulo nos tecidos fotossintetizantes e em crescimento (BEZERRA et al., 2005). Por outro lado, verifica-se efeito positivo dos FMA que resultou na diminuição dos teores de $\mathrm{Na}$ e $\mathrm{Cl}$ a partir do nível de salinidade de água de 3,0 $\mathrm{dS} \mathrm{m}^{-1}$, em relação às plantas não inoculadas (Figuras 7 e 8). Os menores teores desses íons potencialmente tóxicos pode ter contribuído, pelo menos em parte, para a manutenção de maiores taxas fotossintéticas nas plantas micorrizadas (Figura 3c). Tian et al. (2004) também constataram que o aumento de $\mathrm{NaCl}$ do solo proporcionou um aumento nos teores de $\mathrm{Na}$ e $\mathrm{Cl}$ na parte aérea das plantas inoculadas e não inoculadas com FMA.

De acordo Latef e Chaoxing (2011), trabalhando com Glomus mosseae, e Evelin, Giri, e Kapoor (2012), trabalhando com Glomus intraradices, a presença do FMA previne o acúmulo excessivo de $\mathrm{Na}$ em plantas sob estresse salino, o que contribui para o aumento da tolerância ao estresse. Porém, trabalho desenvolvido com plantas lenhosas demonstrou que a inoculação com várias espécies de fungos não teve nenhum efeito sobre a absorção de Na (MAROSZ, 2012). Já em plantas de sorgo verificaram-se maiores teores deste elemento em plantas inoculadas do que nas não inoculadas (LAEI et al., 2011). Esses resultados, em conjunto com os observados no presente estudo, indicam que esta resposta pode depender da espécie vegetal, dos fungos utilizados, da intensidade do estresse salino e das condições de cultivo.

Tanto as plantas inoculadas quanto as não inoculadas com FMA apresentaram aumento no conteúdo de $\mathrm{Na}$ com o aumento dos níveis de salinidade, ajustando-se, respectivamente, aos modelos linear e quadrático (Figura 7d). Esse resultado pode ser conseqüência da maior absorção do elemento $\mathrm{Na}$, dada sua disponibilidade na solução do solo. Al-karaki, Hammad e Rusan (2001), estudando a cultura do tomate, também constataram que tanto as plantas inoculadas como as não inoculadas com FMA apresentaram aumento no conteúdo de $\mathrm{Na}$ com o aumento da $\mathrm{CE}$ da água de irrigação. Observando a Figura 7d também é possível verificar que os conteúdos de sódio nas plantas inoculadas com FMA foram maiores que nas plantas não inoculadas, especialmente nos 
tratamentos de baixa salinidade, o que pode ser explicado pelo maior crescimento destas plantas (Figura 1).

$\mathrm{O}$ conteúdo de $\mathrm{Cl}$ diferiu significativamente com os níveis crescentes de salinidade da água e com a associação simbiótica com FMA. Apesar dos conteúdos de $\mathrm{Cl}$ apresentarem diferenças significativas em relação aos níveis de salinidade, eles não se ajustaram a nenhum modelo de regressão nas plantas inoculadas com FMA, enquanto que nas plantas não inoculadas houve uma tendência linear de aumento (Figura 8d). É interessante ressaltar que o conteúdo de cloreto nas plantas inoculadas com FMA foi maior do que nas plantas não inoculadas até o tratamento salino de $3,0 \mathrm{dS} \mathrm{m}^{-1}$, sendo, a partir daí, observado um tendência inversa.

Figura 7. Teores de sódio nas folhas mais novas (a), folhas mais velhas (b) e caules + pecíolos (c), e total extraído por planta (d) em meloeiro inoculado ( $\downarrow$ ) e não inoculado ( $\square$ ) com FMA cultivado em níveis crescentes de salinidade. Significativo a $\mathrm{p}<0,01(* *)$ e $\mathrm{p}<0,05(*)$ pelo teste $\mathrm{F}$.

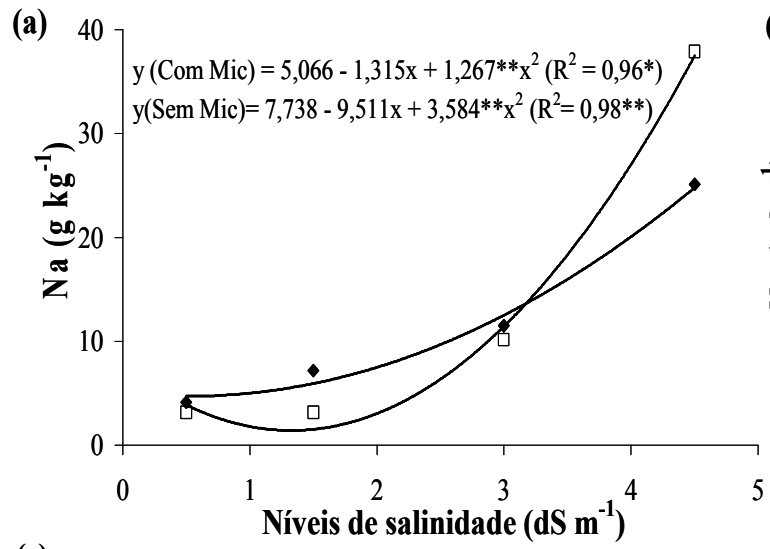

(c)

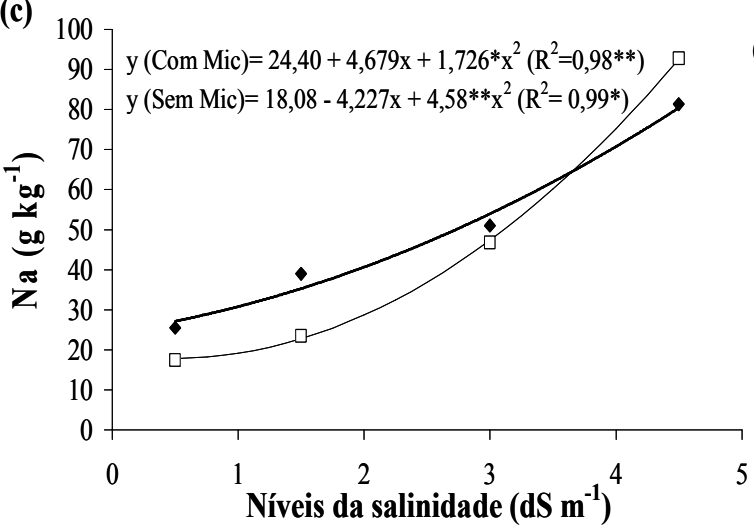

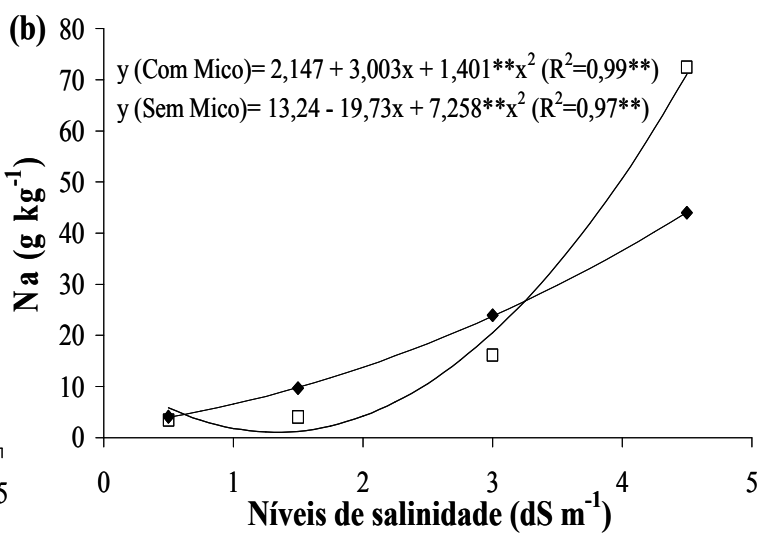

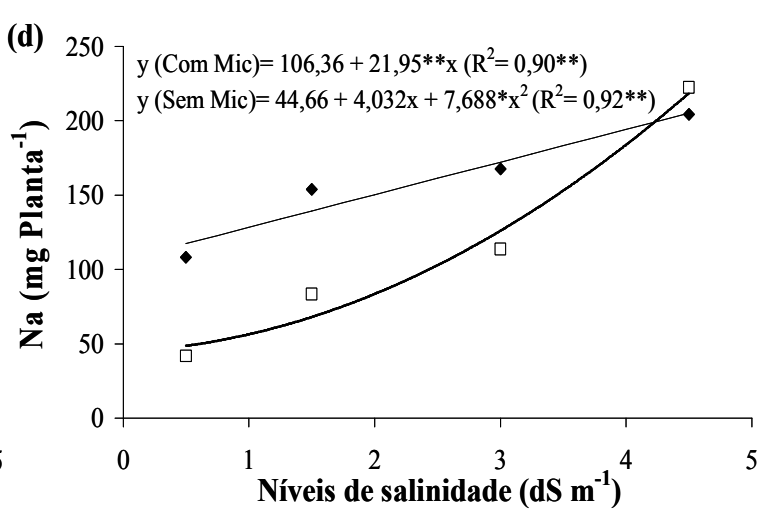

Fonte: Elaboração dos autores. 
Figura 8. Teores de cloreto nas folhas mais novas (a), folhas mais velhas (b) e caules + pecíolos (c), e total extraído por planta (d) em meloeiro inoculado ( $\downarrow$ ) e não inoculado ( $\square$ ) com FMA cultivado em níveis crescentes de salinidade. Significativo a $\mathrm{p}<0,01(* *)$ e $\mathrm{p}<0,05(*)$ pelo teste $\mathrm{F}$; ${ }^{\text {NS }}$ não significativo.
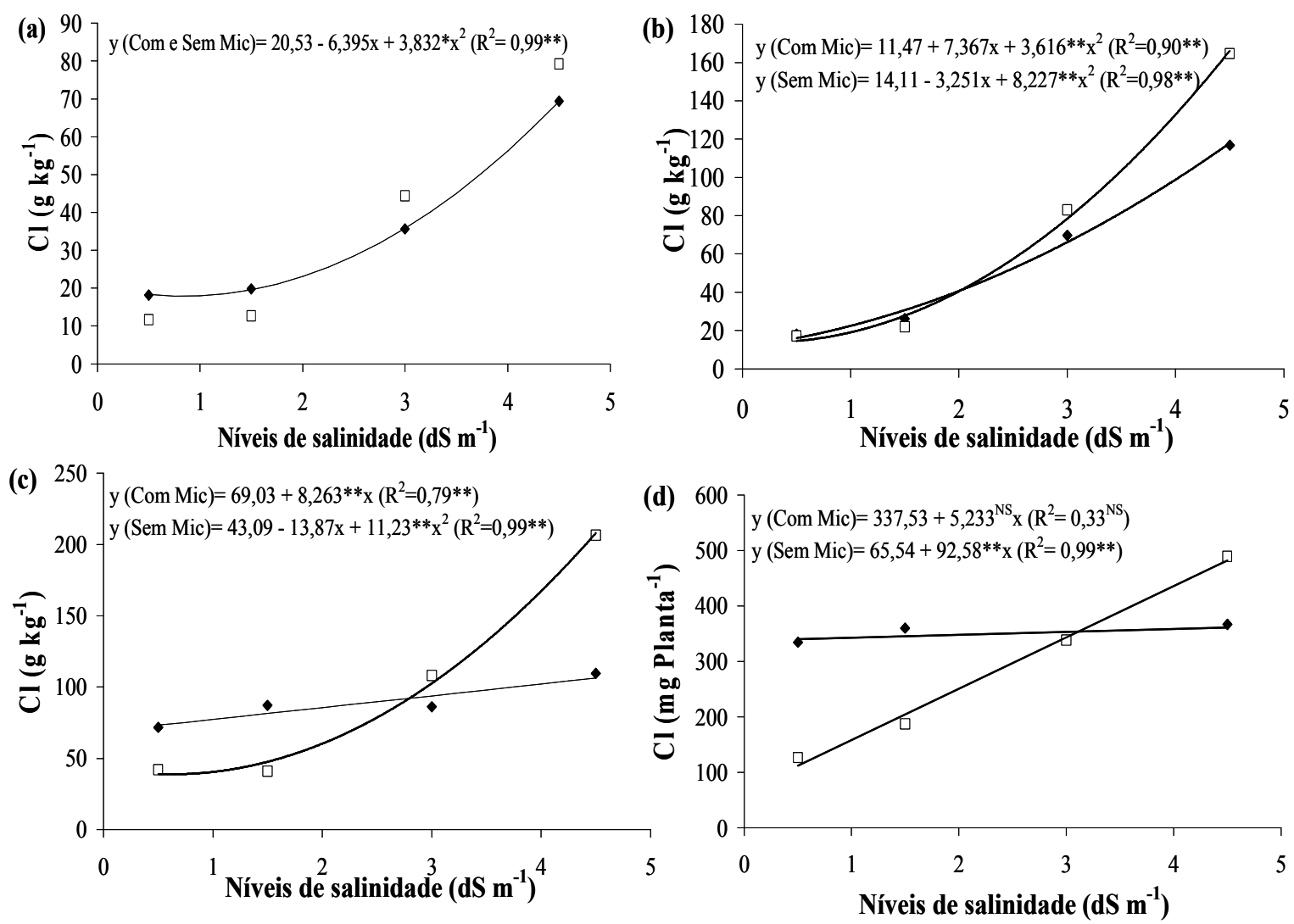

Fonte: Elaboração dos autores.

\section{Conclusões}

A associação com os FMA proporcionou incremento no crescimento e nos totais extraídos de $\mathrm{N}$, P e K pelo meloeiro, porém esses efeitos foram menos expressivos nos maiores níveis de salinidade da água de irrigação. A condutância estomática, a taxa de transpiração e a taxa fotossintética foram influenciadas de forma positiva pela associação do meloeiro com os FMA, o que pode estar associado à redução na absorção dos íons potencialmente tóxicos $(\mathrm{Na}$ e $\mathrm{Cl})$, pelo menos a partir da salinidade da água de irrigação de $3,0 \mathrm{dS} \mathrm{m}^{-1}$. A salinidade reduziu a colonização micorrízica, especialmente nos níveis superiores a $1,36 \mathrm{dS} \mathrm{m}^{-1}$, o que pode limitar o papel das micorrizas em solos de elevada salinidade.

\section{Agradecimentos}

Os autores agradecem ao Instituto Nacional de Ciência e Tecnologia em Salinidade - INCTSal, ao Conselho Nacional de Desenvolvimento Científico e Tecnológico - CNPq e á Fundação Cearense de Apoio ao Desenvolvimento Científico e Tecnológico, pelo suporte financeiro.

\section{Referências}

AL-KARAKI, G. N. Growth of mycorrhizal tomato and mineral acquisition under salt stress. Mycorrhiza, Cambridge, v. 10, n. 2, p. 51-54, 2000.

AL-KARAKI, G. N.; HAMMAD, R.; RUSAN M. Response of two tomato cultivars differing in salt tolerance to inoculation with mycorrhizal fungi under salt stress. Mycorrhiza, Cambridge, v. 11, n. 1, p. 43-47, 2001. 
ASGHARI, H. R.; MARSCHNER, P.; SMITH, S. E.; SMITH, F. A. Growth response of Atriplex nummularia to inoculation with Arbuscular mycorrhizal fungi at different salinity levels. Plant and Soil, The Hague, v. 273, n. 1-2, p. 245-256, 2005.

BEZERRA, M. A.; LACERDA, C. F.; PRISCO, J. T.; GOMES FILHO, E. Crescimento e fotossíntese de plantas jovens de cajueiro anão precoce sob estresse salino. Revista Brasileira de Engenharia Agrícola e Ambiental, Campina Grande, v. 9, p. 90-94, 2005. Suplemento.

BEZERRA, M. E. J.; LACERDA, C. F.; SOUSA, G. G.; GOMES, V. F. F.; MENDES FILHO, P. F. Biomassa, atividade microbiana e FMA em rotação cultural milho/ feijão-de-corda utilizando-se águas salinas. Revista Ciência Agronômica, Fortaleza, v. 41, n. 4, p. 562-570, 2010.

CANTRELL, I. C.; LINDERMAN, R. G. Preinoculation of lettuce and onion with VA mycorrhizal fungi reduces deleterious effects of soil salinity. Plant and Soil, The Hague, v. 233, n. 2, p. 269-281, 2001.

CARVALHO, L. M.; CORREIA, P. M.; MARTINSLOUÇÃO, M. A. Arbuscular mycorrhizal fungal propagules in a salt marsh. Mycorrhiza, Cambridge, v. 14, n. 3, p. 165-170, 2004.

DAEI, G.; ARDEKANI, M. R.; REJALI, F.; TEIMURI, S.; MIRANSARI, M. Alleviation of salinity stress on wheat yield, yield components, and nutrient uptake using arbuscular mycorrhizal fungi under field conditions. Journal of Plant Physiology, Stuttgart, v. 166, n. 2, p. 617-625, 2009.

DODD, I. C.; PÉREZ-ALFOCEA, F. Microbial amelioration of crop salinity stress. Journal of Experimental Botany, Oxford, v. 63, n. 9, p. 3415-3428, 2012.

EPSTEIN, E. Nutrição mineral de plantas: princípios e perspectivas. São Paulo: EDUSP, 1975. 341 p.

EVELIN, H.; GIRI, B.; KAPOOR, R. Contribution of Glomus intraradices inoculation to nutrient acquisition and mitigation of ionic imbalance in $\mathrm{NaCl}$-stressed Trigonella foenum-graecum. Mycorrhiza, Cambridge, v. 22, n. 3, p. 203-217, 2012.

GAINES, T. P.; PARKER, M. B.; CASCHO, G. J. Automated determination of chlorides in soil and plant tissue by sodium nitrate. Agronomy Journal, Madison, v. 76, n. 3, p. 371-374, 1984.

GARCÍA, I. V.; MENDOZA, R. E. Arbuscular mycorrhizal fungi and plant symbiosis in a saline-sodic soil. Mycorrhiza, Cambridge, v. 17, n. 3, p. 167-174, 2007.
GIRI, B.; KAPOOR, R.; MUKERJI, K. G. Influence of arbuscular mycorrhizal fungi and salinity on growth, biomass, and mineral nutrition of Acacia auriculiformis. Biology and Fertility of Soils, Heidelberg, v. 38, v. 38, p. 170-175, 2003.

GRANGEIRO, L. C.; CÉliO FILHO, A. B.; BRAZ, L. T.; GONÇALVES, F. C. Melão amarelo - cultivo. Jaboticabal, UNESP, 2002. 30 p.

JUNIPER, S.; ABBOTT, L. K. Soil salinity delays germination and limits growth of hyphae from propagules of arbuscular mycorrhizal fungi. Mycorrhiza, Cambridge, v. 16, n. 5 , p. $371-379,2006$.

LAEI, G.; KHAJEHZADEH, M. H.; AFSHARI, H.; EBADI, A. G.; ABBASPOUR, H. Effect of mycorrhiza symbiosis on the Nacl salinity in Sorghum bicolor. African Journal of Biotechnology, Abraka, v. 10, n. 40, p. 7796-7804, 2011.

LATEF, A. A. H. A.; CHAOXING, H. Effect of arbuscular mycorrhizal fungi on growth, mineral nutrition, antioxidant enzymes activity and fruit yield of tomato grown under salinity stress. Scientia Horticulturae, Amsterdam, v. 127, n. 3, p. 228-233, 2011.

MAATHUIS, F. J. M.; AMTAMANN, A. $\mathrm{K}^{+}$nutrition and $\mathrm{Na}^{+}$toxicity: the basis of cellular $\mathrm{K} / \mathrm{Na}^{+}$rations. Annals of Botany, Oxford, v. 84, n. 2, p. 123-133, 1999.

MALAVOLTA, E.; VITTI, G. C.; OLIVEIRA, S. A. Avaliação do estado nutricional das plantas: princípios e aplicações. 2. ed. Piracicaba: POTAFOS, 1997. 319 p.

MARDUKHI, B.; REJALI, F.; DAEI, G.; ARDAKANI, M. R.; MALAKOUTI, M. J.; MIRANSARI, M. Arbuscular mycorrhizas enhance nutrient uptake in different wheat genotypes at high salinity levels under field and greenhouse conditions. Comptes Rendus Biologies, Paris, v. 334, n. 7, p. 564-571, 2011.

MAROSZ, A. Effect of green waste compost and mycorrhizal fungi on calcium, potassium, and sodium uptake of woody plants grown under salt stress. Water, Air, \& Soil Pollution, Heidelberg, v. 223, n. 2, p. 787800, 2012.

MARSCHNER, H. Mineral nutrition of higher plants. San Diego: Academic Press, 1995. 889 p.

MIRANDA, J. C. C.; MIRANDA, L. N. Dependência micorrízica de diferentes culturas anuais, adubos verdes e pastagens em solos de cerrado. Planaltina: EMBRAPACPAC, 2004. 3 p. (Comunicado técnico, 144). 
PHILLIPS, J. M.; HAYMAN, A. S. Improved procedures for clearing roots and staining parasitic and vesiculararbuscular mycorrhizal fungi for assessment of infection. Transactions of the British Mycological Society, London, v. 55 , n. 1 , p. $158-161,1970$.

PLENCHETTE, C.; FORTIN, J. A.; FURLAN, V. Growth responses of several plant species to mycorrhizae in a soil of moderate P-fertility. I. Mycorrhizal dependency under field conditions. Plant and Soil, The Hague, v. 70, n. 2, p. 199-209, 1983.

RIBEIRO JÚNIOR, J. I. Análises estatísticas no SAEG. Viçosa: UFV, 2001. 301 p.

RUIZ-LOZANO, J. M.; AZCÓN, R. Symbiotic efficiency and infectivity of an autochthonous Arbuscular mycorrhizal Glomus sp. from saline soils and Glomus deserticola under salinity. Mycorrhiza, Cambridge, v. 10, n. 2, p. 137-143, 2000.

SAINT-ETIENNE, L.; PAUL, S.; IMBERT, D.; DULORMNE, M.; MULLER, F.; TORIBIO, A.; PLENCHETTE, C.; BÂ, A. M. Arbuscular mycorrhizal soil infectivity in a stand of the wetland tree Pterocarpus officinalis along a salinity gradient. Forest Ecology and Management, Amsterdam, v. 232, n. 1-3, p. 86-89, 2006.
SHARIFI, M.; GHORBANLI, M.; EBRAHIMZADEH, H. Improved growth of salinity-stressed soybean after inoculation with salt pre-treated mycorrhizal fungi. Journal of Plant Physiology, Stuttgart, v. 164, n. 9, p. 1144-1151, 2007.

SHENG, M.; TANG, M.; CHEN, H.; YANG, B; ZHANG, F.; HUANG, Y. Influence of arbuscular mycorrhizae on photosynthesis and water status of maize plants under salt stress. Mycorrhiza, Cambridge, v. 18, n. 6-7, p. 287296, 2008.

TAVARES, R. C.; MENDES FILHO, P. F.; LACERDA, C. F.; SILVA, J. Colonização micorrízica e nodulação radicular em mudas de sabiá (Mimosa caesalpiniaefolia Benth.) sob diferentes níveis de salinidade. Revista Ciência Agronômica, Fortaleza, v. 43, n. 4, p. 409-416, 2012.

TIAN, C. Y.; FENG, G.; LI, X. L.; ZHANG, F. S. Different effects of arbuscular mycorrhizal fungal isolates from saline or non-saline soil on salinity tolerance of plants. Applied Soil Ecology, Amsterdam, v. 26, n. 2, p. 143-148, 2004.

YANO-MELO, A. M.; SAGGIN, O. J.; MAIA, L. C. Tolerance of mycorrhized banana (Musa sp. cv. Pacovan) plantlets to saline stress. Agriculture, Ecosystems and Environment, Zurich, v. 95, n. 1, p. 343-348, 2003. 